\title{
O Trabalho do Assistente Social no Poder Judiciário: a realização do estudo social e a elaboração do parecer técnico
}

\section{The Social Assistant Work in Judiciary Power: the realization of social study and the elaboration of technical report}

Mônica Santos Barison ${ }^{1}$

Palavras-chaves:

Trabalho do

Assistente Social

Parecer Social

Campo Sócio-

Jurídico

\section{Resumo}

Artigo

Original

Original

Paper

Este artigo pretende contribuir no processo de sistematização do debate acerca do trabalho do assistente social no Tribunal de Justiça, com ênfase nos aspectos teórico-metodológicos, ético-políticos e técnico-operativos que fundamentam a realização do estudo e a elaboração do parecer social. $\mathrm{O}$ debate ora travado aglutina as proposições de diferentes autores que abordam a temática, na perspectiva de elucidar a produção científica sobre o trabalho do assistente social no campo sócio-jurídico. Neste espaço sócio-ocupacional, a feitura do estudo social e a emissão do parecer têm sido identificadas como atividades que, historicamente, marcaram o exercício profissional. Assim, consideramos relevante produzir questões que contribuam com a qualificação do assistente social para o desempenho de tais funções. Outrossim, este material servirá de subsídio didático para a disciplina que compõe a grade curricular do Curso de Serviço Social do UniFOA, intitulada "0 Serviço Social e o Campo Sócio-Jurídico”.

\begin{abstract}
This article intends to contribute in the process of systematization in the debate about the social assistant work in the Tribunal of Justice, with emphasis in the theorical-methodological, ethic-political and technicaloperational aspects which fundament the realization of the study and the elaboration of the Social Technical Report. The debate now developed joins the propositions from different authors which approach the theme, in order to elucidate the scientific production about the social assistant work in the social-judicial field. In this social-occupational space, the making of a social study and the emission of technical report have been identified as activities which, historically, marked the professional actuation. This way, we consider relevant to produce questions which contribute to the social assistant qualification for performing such jobs. Therefore, that material will be a didactical subsidy for a discipline which is part of the curriculum of Social Service Course in UniFOA entitled "The Social Service and the Social-Judicial Field"
\end{abstract}

Key words:

Social Assistant Work

Technical Report

Social-Judicial Field

\section{Introdução}

Segundo Fávero (2003), a realização que o sentido atribuído a esta atividade tem se de estudo social e a elaboração de parecer podem ser reconhecidas como atividades que sempre marcaram o exercício profissional do assistente social no Poder Judiciário, em específico no Tribunal de Justiça. Observa-se, entretanto, alterado ao longo da história do Serviço Social.

É sabido que o próprio significado da profissão está atrelado às transformações societárias, plasmadas em um determinado contexto histórico. (IAMAMOTO, 2000). Então, 
não podemos compreender o Serviço Social deslocado do movimento das configurações das relações sociais, em específico das relações Estado-Sociedade.

Tais relações, no dizer de Iamamoto,"condicionam o trabalho concreto a ser realizado e seus efeitos no processo de reprodução das relações sociais. Forjam, assim, específicas condições e relações sociais por meio das quais se realiza o exercício profissional no mercado de trabalho" (IAMAMOTO 2005: 18).

Nesse sentido, mais do que construir habilidades técnico-operativas para realizar um estudo social e elaborar um parecer técnico, identifica-se a importância de compreender o processo histórico de (des)construção do (s) significado (s) do Serviço Social, reconhecendo os pressupostos de análise da profissão que compõem o debate contemporâneo.

Assim, a primeira sessão deste artigo pretende se constituir, exatamente, do debate que versa sobre a inserção do assistente social em processos de trabalho, destacando os elementos constitutivos do trabalho do assistente social no Tribunal de Justiça. No bojo deste debate, está inscrita a análise sobre os fundamentos teórico-metodológicos, éticopolíticos e técnico-operativos do Serviço Social na contemporaneidade. Considera-se que, reconhecer a articulação entre estes três eixos que fundamentam o trabalho do assistente social é de extrema importância para qualificar o exercício de qualquer atividade profissional.

A segunda sessão do artigo é composta por temáticas que pretendem destacar o debate acerca dos aspectos teórico-metodológico, ético-político e técnico-operativo da realização do estudo e da emissão do parecer social.

Em um primeiro momento, dar-se-á ênfaseàs duas dimensões do trabalho do assistente social: a interventiva e a investigativa.

$\mathrm{O}$ atributo central da ação profissional se constrói a partir da demanda que é posta, historicamente, ao Serviço Social. O assistente social tem sido acionado para intervir no processo de produção e reprodução das relações sociais, seja no nível da reprodução material ou no nível da reprodução subjetiva dos sujeitos que compõe as classes sociais (IAMAMOTO, 2000).

Tal intervenção pressupõe que o profissional tenha habilidades para analisar o conjunto das relações sociais nas quais pretende intervir. Aqui reside a dimensão investigativa do exercício profissional. O assistente social precisa construir mediações para desvelar a realidade que o cerca, na perspectiva de produzir conhecimentos acerca do seu objeto de intervenção.

Destaca-se que tais dimensões do exercício profissional devem ser compreendidas em uma perspectiva dialética: não se pode considerar que intervir e investigar são momentos diferenciados e fragmentados da ação profissional. Na medida em que se investiga, modifica-se a realidade e quando se intervém, se produz conhecimentos. Neste sentido, é de fundamental importância estudar a instrumentalidade do exercício profissional, que, segundo Guerra (2000), é compreendida como o conjunto das capacidades construídas historicamente pela categoria profissional para materializar estas duas dimensões do exercício profissional e, conseqüentemente, responder as demandas apresentadas pelo mercado de trabalho.

Frente ao exposto, as temáticas seguintes que configuram a segunda sessão do artigo pretendem, justamente, estabelecer a conexão entre a primeira unidade e este debate sobre as dimensões do trabalho do assistente social.

O estudo social e o parecer técnico compõem, em uma primeira análise, a dimensão investigativa do exercício profissional, compreendida aqui como uma dimensão que aglutina a atividade de pesquisa situada no campo das ciências sociais.

Silva (2000) pontua que, quando o assistente social é acionado para elaborar um parecer social, a demanda que lhe é apresentada se situa em torno da produção de conhecimentos acerca da vida de sujeitos sociais para subsidiar as decisões de outrem.

Mas que demandas são essas? Como responder essas demandas? Que sentido éticopolítico atribuir a esse trabalho? A partir de que fundamentos teórico-metodológico, éticopolítico e técnico-operativo deve-se executar essa atividade profissional? Como fazer o estudo social? Como elaborar o parecer técnico?

Longe de pretender apresentar respostas para estas e outras questões, este artigo objetiva ainda construir subsídios didáticos para a disciplina do Curso de Serviço Social do UniFOA, intitulada "Serviço Social e o Campo Sócio-Jurídico". 


\section{Processos de Trabalho e Serviço Social}

Marilda Iamamoto indica que, na década de 1980, inaugurou-se um novo debate acerca do Serviço Social, situando-o como "uma especialização do trabalho coletivo, dentro da divisão social e técnica do trabalho, partícipe do processo de produção e reprodução das relações sociais".(IAMAMOTO, 2000: 83).

Segundo a referida autora, este debate reconhece que o Serviço Social está inscrito em relações e processos de trabalho.

Postula que, identificar a inserção da profissão em processos de trabalho, é reafirmar a centralidade do trabalho como organizador da vida social.

"O trabalho é uma atividade fundamental do homem, pois mediatiza a satisfação de suas necessidades diante da natureza e de outros homens. Pelo trabalho o homem se afirma como um ser social e, portanto, distinto da natureza...O trabalho é, pois, o selo distintivo da atividade humana. Primeiro porque o homem é o único ser que, ao realizar o trabalho, é capaz de projetar, antecipadamente, na sua mente, o resultado a ser obtido...Mas o homem também é o único ser que é capaz de criar meios e instrumentos de trabalho, afirmando essa atividade caracteristicamente humana." (IAMAMOTO, 2000:89)

A autora considera que, pensar o Serviço Social como trabalho, é ampliar e reconfigurar a análise sobre a chamada "prática profissional". Pontua que avaliar qualquer processo de trabalho é levar em consideração não só a ação "propriamente dita" do profissional, mas destacar a matéria prima ou objeto que incide sua ação e ainda os meios de trabalho que potenciam a ação do sujeito sobre o objeto.

Nesse sentido, identificar os elementos constitutivos do trabalho do assistente social é de fundamental relevância para compreender o sentido que se deseja atribuir a qualquer atividade que seja desempenhada por este profissional.

Entretanto, anterior a análise acerca dos os elementos constitutivos do trabalho do assistente social no Tribunal de Justiça, faz-se necessário aprofundar o debate contemporâneo sobre o Serviço Social, travado por Iamamoto. A autora apresenta três pressupostos para analisar a profissão na contemporaneidade.

O primeiro postula que é preciso compreender a profissão inscrita no próprio movimento da história. O Serviço Social é parte e é expressão da realidade social, da relação das classes sociais com o Estado. Este pressuposto rompe com uma visão que analisa a profissão apenas a partir do seu próprio interior. Exige do assistente social a capacidade de decifrar a realidade e construir propostas de trabalho criativas, capazes de decifrar a realidade e efetivar direitos.

Tal capacidade exige ainda a ruptura com atividades burocráticas, situando o profissional como planejador, gerenciador, avaliador de políticas sociais e não um simples executor. Exige também a ruptura com a perspectiva de que o assistente social é o "messias", a "fada madrinha", que em um "passe de mágicas", apresentará todas as possibilidades para a transformação da realidade.

A autora explicita que as alternativas estão inscritas na própria realidade, cabendo ao assistente social potencializar tais possibilidades. Outra ruptura necessária a ser feita é a de ultrapassar a visão determinista e fatalista, como se a realidade já estivesse dada e fosse impossível alterá-la.

O segundo pressuposto é aquele que indica que é preciso compreender o serviço social como um tipo de trabalho, inscrito na divisão sócio-técnica do trabalho coletivo na sociedade capitalista. Este pressuposto rompe definitivamente com a visão de que o serviço social é especialização da filantropia. O exercício profissional está condicionado pelo movimento da relação entre a sociedade civil e o Estado. Este pressuposto implica em compreender o assistente social como trabalhador assalariado, que vende sua força de trabalho. O produto do trabalho do assistente social tem um valor social, que corresponde às expectativas da sociedade capitalista. Neste sentido é necessário que o assistente social esteja ciente da direção éticopolítica que pretende dar ao seu trabalho.

O terceiro pressuposto apontado pela autora nos faz compreender que a profissão intervém diretamente no processo de produção e reprodução da vida social.

Este processo nos remete à compreensão da organização da sociedade capitalista, que tem como "característica" básica a concentração de riquezas socialmente produzidas nas mãos de poucos. $\mathrm{O}$ trabalho do assistente social incide na (re) construção de representações sociais e conseqüentemente no comportamento dos sujeitos, tendo em vista o caráter educativo de seu trabalho. Incide ainda na reprodução material da classe trabalhadora, na medida em que media a concessão de bens e 
serviços a determinadas parcelas da população.

A identificação de tais pressupostos ilumina, então, a compreensão sobre a inserção do Serviço Social em processos de trabalho.

A autora afirma que "o serviço social tem na questão social a base de sua fundação como especialização do trabalho" (IMAMOTO, 2000:27). O assistente social é requisitado para construir propostas de enfrentamento das mais diversas expressões da questão social. A autora define questão social, como o conjunto das diversas expressões das desigualdades sociais, produzida pela concentração de bens e riquezas. A questão social é, então, o primeiro elemento constitutivo do trabalho do assistente social: é a matéria-prima ou objeto de seu trabalho.

Entretanto, na condição de assalariado, o profissional depende de meios de trabalho para efetuar sua atividade. Iamamoto descreve que meios de trabalhos não devem ser reduzidos a instrumentos de trabalho, a um conjunto de técnicas. Os meios de trabalho são aqueles oferecidos pela instituição empregadora: recursos financeiros, materiais, humanos e ainda as diretrizes, objetivos, metas, definições de papéis e funções. Assim, a instituição, conforme a autora, "não é um condicionante a mais do trabalho do assistente social. Ela organiza o processo de trabalho do qual ele participa".(IAMAMOTO, 2000: 63).

E o terceiro elemento constitutivo do trabalho do assistente social? A autora aponta que o trabalho propriamente dito do assistente social é uma atividade humana, assim como outras, exercida por sujeitos de classes, que "são portadores de uma herança cultural, de uma bagagem teórica e técnica, de valores éticosociais." (IAMAMOTO, 2000:64).

A autora pontua que o acúmulo teórico da categoria profissional, levado a cabo pelo movimento de reconceituação dos anos 80 , imprimiu novos rumos à história da profissão, na construção de novos referenciais para a compreensão de seu exercício profissional. $\mathrm{O}$ projeto ético-político, materializado no Código de ética do assistente social, aponta, dentre outros, para a defesa intransigente dos direitos sociais, políticos e humanos, situando o profissional como facilitador e mediador do acesso da população a estes direitos, mediados pelas políticas sociais.

Tal processo de reconceituação lançou, também, novas bases para transformações na formação profissional, que apontam para a necessidade de articulação entre os eixos teórico-metodológicos, ético-políticos e técnicooperativos da intervenção profissional, situando o assistente social como intelectual, cujos processos de trabalho interferem na produção e reprodução da vida social. $\mathrm{O}$ assistente social necessita, então, decifrar essa realidade social.

Através de atitude investigativa, deve se apropriar da atividade de pesquisa como indispensável ao seu exercício profissional. Rompe-se aqui, com a compreensão de que os instrumentos do trabalho do assistente social são arsenais de técnicas, situando-os no campo das bases teórico-metodológicas: tal referencial teórico é o recurso essencial que o profissional deve acionar para exercer o seu trabalho.

A autora propõe a superação da análise que identifica o exercício profissional como prática do assistente social. Propõe uma compreensão mais abrangente, que identifica o exercício profissional como trabalho do assistente social. Tal mudança não é simples alteração da nomenclatura.

A autora coloca que, tradicionalmente, o exercício profissional do assistente social tem sido identificado a partir da categoria prática, vinculando-a a chamada práxis social. A crítica feita pela autora sobre esta compreensão é que, nela, não há uma diferenciação entre o exercício profissional do assistente social e qualquer outra ação, de qualquer sujeito, no campo das relações sociais. Fala ainda que a prática é identificada, reduzidamente, como o conjunto das atividades do assistente social, atividade esta socialmente determinada.

A autora pontua que a identificação do exercício profissional como trabalho, amplia as possibilidades de análise da profissão. Fala que o conjunto de atividades do assistente social deve ser considerado apenas como um dos elementos constitutivos do processo de trabalho do assistente social.

Nesse contexto, a autora discute a autonomia do assistente social. O trabalho deste profissional não depende somente de sua ação: está condicionado pela sua condição de assalariamento.

A ação criadora do assistente social está determinada pelas exigências impostas de seu empregador, que tem o direito de utilizála conforme as políticas, diretrizes, objetivos e recursos da instituição; Porém, identifica que é, nesse cenário, que se materializa a autonomia do assistente social, pois o controle exercido sobre 
o desempenho de suas atividades é diferenciado. Identifica a autora que o instrumento básico do trabalho do assistente social é a linguagem. A execução de suas atividades está intimamente relacionadaàsuaformaçãoteórico-medotológica, ético-política e técnico-operativa. $\mathrm{O}$ assistente social atua diretamente com os sujeitos sociais, estabelecendo vínculos específicos com os usuários das políticas sociais.

A autora aponta, então, que estes elementos (o tipo de controle exercido sobre o trabalho do assistente social e o uso da linguagem), podem propiciar sua autonomia. Seu trabalho situa-se no campo político-ideológico. Historicamente, o assistente social vem sendo requisitado para exercer funções de controle e adaptação dos sujeitos sociais à ideologia da classe dominante. Mas a própria natureza da especialização do seu trabalho pode abrir brechas e possibilidades de reorientar o sentido de suas ações, na perspectiva de construção da cidadania, efetivação de direitos, formação de cultura pública democrática.

A consolidação do projeto éticopolítico do serviço social não está desconectando do processo mais abrangente de construção de um novo projeto societário. Assim, a articulação com os diversos movimentos sociais é a energia e alimento para a manutenção e consolidação deste projeto.

\subsection{Os elementos constitutivos do trabalho do assistente social no Tribunal de Justiça}

Qual é a matéria-prima do trabalho do assistente social no Tribunal de Justiça? Conforme explicitado anteriormente, a questão social tem sido reconhecida como a matéria prima do trabalho do assistente social. Compartilha-se aqui da definição de Iamamoto sobre questão social:

\footnotetext{
"Conjunto das expressões das desigualdades sociais da sociedade capitalista madura, que tem uma raiz comum: a produção é cada vez mais coletiva, o trabalho tornase mais amplamente social, enquanto a apropriação dos seus frutos mantém-se privada, monopolizada por uma parte da sociedade”. (IAMAMOTO, 2000: 27)
}

Na perspectiva de entender quais são as expressões da questão social que se constituem como objeto de trabalho para o assistente social do Poder Judiciário, é importante compreender os tipos de demandas que se apresentam para o próprio Tribunal de Justiça.

No Poder Judiciário, por exemplo, observa-se um crescimento das ações judiciais que tramitam nas Varas de Família e nas Varas de Infância, Juventude e Idoso.

O próprio território em que estamos inseridos podeserassumido comoilustração deste crescimento: é só observar que, inicialmente, em Volta Redonda, existiam: uma Primeira Vara de Família e uma outra (chamada de Segunda Vara de Família) que também aglutinava as questões relativas a Infância e Juventude. Atualmente, existem três Varas de Família e um Juizado para Infância, Juventude, sendo que este incorporou, recentemente, a questão do Idoso.

E quais são as principais ações que tramitam, por exemplo, na Vara de Família? Na Vara de Família, observa-se a existência de ações que expressam e evidenciam: 1) conflitos ou impasses frente a questões relativas à dinâmica de vida das famílias 2) movimentos significativos de reorganização das composições das famílias na sociedade contemporânea 3) a necessidade de instrumentos jurídicos para o reconhecimento e a legitimação de relações familiares, na perspectiva da busca pela garantia de direitos.

Então, são, por exemplo, ações que tramitam nestas Varas de Família: separação litigiosa ou consensual; guarda e responsabilidade, regulamentação de visita; alimentos; reconhecimento ou negatória de paternidade; interdição, etc. Utilizando uma linguagem metafórica, pode-se dizer que, na verdade, esses processos são "a ponta de um enorme iceberg".

É preciso compreender que as demandas que são apresentadas pelos sujeitos, representados pelos advogados, ao Poder Judiciário, não são apenas problemas individuais, mas expressam o modo como as relações sociais vêm sendo produzidas e reproduzidas na sociedade capitalista.

É preciso considerar que as relações interpessoais e intersubjetivas são construções históricas, vinculadas a um processo de socialização coletiva na qual os sujeitos estão inseridos. Compreender as formas de sociabilidade humana, determinadas pelo modo de produção capitalista é de fundamental importância para não corrermos o risco de analisar os processos judiciais como problemas individuais, mas de situá-los em um contexto de forma ampliada. E é preciso construir mediações, 
em sua dimensão reflexiva, para estabelecer conexões entre o singular (que se apresenta no cotidiano da instituição) e o universal, que se expressa no conjunto das relações sociais (PONTES, 1997).

Observa-se que o modo de produção capitalista, desde o final do século XX, vem sofrendo profundas transformações, que afetam diretamente o mundo do trabalho e conseqüentemente as formas de sociabilidade entre os homens (ANTUNES, 2002).

Não é objetivo deste artigo falar, em específico, destas transformações. Mas, em linhas gerais, identifica-se o seguinte debate acerca das alterações das formas de sociabilidade, que são decorrentes da implantação do projeto neoliberal:

- Assiste-se transformações significativas no processo de reprodução material dos homens na sociedade capitalista. A redução dos postos de trabalho, a flexibilização das relações trabalhistas, a invasão da tecnologia no sistema de produção, a valorização do mercado financeiro em detrimento do mercado de produção têm impedido um grande contingente populacional de vender a sua força de trabalho para garantir sua própria sobrevivência. Isso implica dizer que o processo de pauperização da população nunca atingiu níveis tão comprometedores;

- Assiste-se também o esgaçamento do tecido social, o desmantelamento de projetos societários que defendam os interesses da classe que vive do trabalho. Este fenômeno compromete os vínculos sociais de determinados grupos e segmentos da população e, conseqüentemente, sua capacidade de mobilização para apresentar qualquer tipo de resistência e enfrentamento frente à violação de direitos. $\mathrm{O}$ projeto neoliberal desarticulou os movimentos sociais, populares ou sindicais para que as reivindicações destes grupos não precisassem entrar na agenda da ordem societária. Assim, no plano das micro-relações, compromete-se o sentimento de pertença dos sujeitos sociais, que absorvem, cada vez, mais valores liberais (como o individualismo, a competição, a noção de propriedade privada).

- Assiste-se ainda o desmoronamento dos sistemas de proteção social e conseqüentemente a noção de Estado Social. A implantação do projeto do Estado Mínimo está em franco movimento e acompanha- se o desmantelamento das políticas sociais, que são cada vez mais focalizadas, seletivas e compensatórias; o que compromete o acesso a serviços de saúde, assistência social e de educação com qualidade. O estado vem se desresponsabilizando de sua função de construir sistema de proteção social e vem transferindo tal responsabilidade para a própria sociedade civil.

Se o olhar for lançado para a instituição família, queéaprimeirainstituiçãodesocialização em que os sujeitos são inseridos, observa-se que ela tem sido atingida duramente por estas transformações no processo de sociabilidade, que ora está inscrito na sociedade capitalista. A família tem encontrado dificuldades em se manter como referência para os seus membros e ainda de cumprir suas funções de reprodução social e cultural.

Neste sentido, as mudanças ocorridas no mundo da família (na suas configurações e dinâmicas) e ainda as dificuldades das mesmas no cumprimento de suas funções, não podem ser "fenômenos" entendidos apenas como expressões de uma revolução cultural ou sexual, mas como expressões do desmantelamento dos projetos societários, do sistema de proteção social e ainda dos processos de reprodução material.

As ações que tramitam no Poder Judiciário, muitas vezes, como indica Marilda Iamamoto (2004), se apresentam como situações limite que "condensam a radicalidade das expressões da questão social em sua vivência pelos sujeitos". Segundo a autora, estes sujeitos buscam a proteção judicial quando todos os outros recursos, principalmente do Poder Executivo, já foram exauridos.

Pode-se afirmar, então, que, identificar a matéria prima do trabalho do assistente social no Poder Judiciário é olhar para além das petições das iniciais dos processos. Que famílias nós encontramos atrás dos processos judiciários? Os seus membros vivenciam quais expressões da questão social? Qual a interferência destas na organização daquele núcleo familiar em específico?

E aí se destaca, por exemplo, o crescimento de famílias chefiadas por mulheres; o crescimento das famílias extensas, cujos membros dependem financeiramente dos idosos; o crescimento de mulheres que se engravidam na adolescência; o crescimento de famílias que sobrevivem apenas com benefícios sociais; o 
crescimento de famílias moradoras de rua; o crescimento de famílias marcadas por relações de violência; o envolvimento de adolescentes com o mundo do crime etc.

Para fundamentar a análise, um texto de Marilda Iamamoto:

"O assistente social não trabalha com fragmentos da vida social, mas com indivíduos sociais que se constituem na vida social em sociedade e condensam em si a vida social. As situações singulares vivenciadas pelos indivíduos são portadoras de dimensões universais e particulares das expressões da questão social, condensadas na história de vida de cada um deles. O conhecimento das condições de vida dos sujeitos permite aos assistentes sociais dispor de um conjunto de informações que, iluminadas por uma perspectiva teórica critica, possibilitam apreender e revelar as novas faces e meandros da questão social, que desafia a cada momento o desempenho profissional: a falta de atendimento às suas necessidades na esfera da saúde, educação, habitação, a assistência; nas precárias condições de vida das famílias; na situação das crianças de rua; no trabalho infantil, na violência doméstica, entre inúmeros exemplos" (IAMAMOTO: 2004, 272)

Frente ao exposto, é mister avaliar, então, como o Poder Judiciário vem respondendo as demandas que lhe são apresentadas. Assim, será iniciado o debate sobre o segundo elemento constitutivo do trabalho do assistente social: os meios de produção oferecidos pela instituição empregadora.

Conforme apresentado anteriormente, o assistente social é trabalhador que vende sua força de trabalho. Ou seja, ele não detém os meios de produção de seu trabalho. Os objetivos, as diretrizes e princípios da instituição, os recursos materiais e humanos que lá existem são de propriedade de seu empregador. Por isso, é de fundamental importância que o assistente social saiba reconhecer quais são os meios que possibilitam o seu trabalho e, principalmente, quais são as demandas apresentadas para o serviço social pelo seu empregador.

Observa-se que o Poder Judiciário é uma instituição secular, que se constituiu como um dos Poderes do Estado Moderno. Segundo José Eduardo Faria (2001), podemos dizer, em linhas gerais, que o Poder Judiciário, historicamente, vem ocupando três funções básicas na sociedade moderna: 1) resolver conflitos (função instrumental) 2) promover o controle social (função política) 3) Promover a socialização das expectativas à interpretação das normas legais (função simbólica).
Este autor pontua que o Poder Judiciário, no período histórico do capitalismo concorrencial, foi concebido para, no exercício de suas funções, preservar a propriedade privada, conferir eficácia aos direitos individuais, assegurar os direitos fundamentais, garantir as liberdades públicas e afirmar o império da lei, protegendo os indivíduos contra os abusos de poder do Estado. No período histórico do capitalismo organizado (configuração dos Estados de Bem-Estar Social), o Poder Judiciário também passou a implementar os direitos sociais, condicionando a formulação e execução de políticas públicas com propósitos compensatórios e distributivistas.

Pode-se analisar que estas funções do Poder Judiciário representam os interesses da classe dominante, na medida em que é constituída para preservar o conjunto de códigos que legitimam a relação entre capitaltrabalho e, conseqüentemente, punir, adaptar, integrar os sujeitos que se mostram "rebeldes" e "transgressores" frente a este conjunto de normas e regras sociais. E aqui, verifica-se que a compreensão dominante sobre os chamados problemas sociais assume a lógica de que eles são frutos dos comportamentos individuais.

Entretanto, se a Constituição Brasileira de 1988 for assumida como referência, o Poder Judiciário dispõe, na atualidade, nos dizeres de Marilda Iamamoto (2004), de uma importância especial na luta pela afirmação e reconhecimento do estatuto de cidadania de parte daqueles que foram alijados em nossa história, colaborando na sua afirmação enquanto sujeitos de direitos.

Assim, baseado do debate de Faria, considera-se que existe uma tensão entre o reconhecimento da cidadania, dos direitos sociais e o processo de preservação dos mecanismos que produzem as desigualdades sociais. Muitas vezes, a prática do Poder Judiciário explicita esta tensão existente entre os interesses individuais e os interesses coletivos

Neste sentido, o Poder Judiciário, por vezes, assume papel paradoxal, como explicita Faria:

"Um, de natureza essencialmente punitiva, aplicável aos segmentos marginalizados; outro, de natureza eminentemente distributiva, o que implica, além da coragem e determinação política, a adoção de critérios compensatórios e protetores a favor desses mesmos segmentos, tendo em vista a instituição de padrões mínimos de equidade, integração e coesão sociais" (FARIA, 2001:17) 
Também, para efeito de análise do poder judiciário, não se pode deixar de mencionar o caráter burocrático e hierárquico desta instituição. Estas características estão atreladas à noção de competência, segundo Faria (2001). A burocracia tem como princípio o culto à autoridade. A competência se mostra, então, através do exercício do poder de quem o detém, que impõe uma obediência aos mecanismos das atividades fixadas em formas e rotinas.

E como o Serviço Social se situa nesta instituição? Quais são as demandas apresentadas ao assistente social nesta instituição? É evidente que a função hegemônica do poder judiciário é transmitida a todos os agentes que integram este Poder, com a expectativa de que a ação de cada um deles materialize e operacionalize os objetivos da instituição. Assim, em linhas gerais, a expectativa é a de que o assistente social também reproduza esta lógica que institui o Poder Judiciário.

Ao Serviço Social, concretamente, vem sendo delegado o papel de realizar os estudos sociais, que são reconhecidos como material que vai subsidiar as decisões dos juizes acerca da matéria de cada processo. Verifica-se que a inserção do assistente social no Poder Judiciário é datada da década de 40, prioritariamente nos Juizados da Infância e Juventude.

Observa-se que o modo como o assistente social vem ocupando este espaço sócio-ocupacional tem se alterado no decorrer da historia; mudanças estas que acompanham a própria dinâmica da instituição e ainda a própria dinâmica da profissão.

Neste sentido, a ação do profissional e, conseqüentemente, o produto de seu trabalho assume, historicamente, contornos diferentes.

Apesar da história nos mostrar que o Serviço Social sempre esteve inserido no poder judiciário, principalmente, nos antigos Juizados de Menores, observa-se que a sistematização do trabalho do assistente social tem sido objeto de debates e pesquisas apenas no final da década de 90 (FAVERO, 2003).

Então, muitos estudos precisam ser desenvolvidos para aprofundar a compreensão do significado, dos objetivos do Serviço Social neste campo.

Baseando-se no debate de Iamamoto (2004), postula-se que existem dois "caminhos" teórico-metodológico, ético-político e técnicooperativo que o assistente social que trabalha no Judiciário pode seguir; "caminhos" estes que foram sendo construídos historicamente pela profissão, inscrita na relação entre o Estado e a sociedade civil:

- O conservador ou tradicional, em que se verifica a adoção de modelo clássico do Serviço Social de Caso para fundamentar suas bases teóricas e mecanismos operacionais (que vai se pautar na distinção entre o normal e o patológico, apoiado em procedimentos descritivos da realidade; que induz uma atuação profissional na linha de adaptação ou integração a uma ordem social tida como imutável e natural; que contribui para o controle e disciplinamento, através da culpabilização dos sujeitos pelas condições socioeconômicas em que vivem; que invade a privacidade dos sujeitos com condutas autoritárias e burocráticas)

- O reconceituado ou crítico, em que o assistente social assume referencial teóricometodológico crítico que é capaz de decifrar a realidade dos sujeitos de forma a construir mediações entre o singular e o universal das relações sociais; que se propõe a captar e reconstruir os processos sociais desencadeadores das situações de vida em nível individual e/ou familiar, nas suas múltiplas relações e determinações; que articula a vida os indivíduos singulares com as dimensões estruturais e conjunturais que a conformam, em uma análise na perspectiva da totalidade.

A partir desta última perspectiva, que é a indicada no atual projeto ético-político da categoria profissional, o trabalho do assistente social assume uma proposta de ser instrumento de viabilização dos direitos civis, políticos e sociais para todos, segundo princípios e valores democráticos.

Tal projeto ético político demanda do assistente social, nos termos de Marilda Iamamoto (2004):

- Atitude investigativa e desenvolvimento de pesquisa, que são dimensões constitutivas do trabalho do assistente social neste campo, tendo em vista que o estudo social pode desvelar a vida dos indivíduos e oferecer importantes subsídios para as decisões dos juizes, no sentido de abrir possibilidades para o acesso das famílias aos seus direitos;

- Compromisso com a socialização das informações junto aos sujeitos envolvidos nas atividades executadas, observando o sigilo profissional; 
- Conhecimento e articulação com a rede de serviços do Poder Executivo, tendo em vista que o Poder Judiciário não elabora ou executa políticas sociais;

- Compromisso com sua formação profissional, para que desenvolva habilidades e competências para analisar a vida social;

- Competência teórica que sustente e garanta sua autonomia profissional no processo de construção do parecer social (escolha dos instrumentos e emissão de avaliações) e não confunda subordinação com subalternidade;

- Competência para o trabalho interdisciplinar.

\subsection{A construção histórica dos fundamentos do Serviço Social}

Frente a esses inúmeros desafios, é o embasamento teórico-metodológico, éticopolítico e técnico-operativo que possibilita o exercício profissional criativo e propositivo, nos dizeres de Marilda Iamamoto (2000).

A construção dos fundamentos do Serviço Social não foi produto apenas de uma movimentação interna da categoria profissional, maspodeserexplicadanomovimentohistórico da sociedade. Conforme explicitado anteriormente, compreende-se que os significados da profissão de Serviço Social foram forjados na relação Estado-Sociedade.

Segundo Yazbek (2000), na gênese do Serviço Social no Brasil, é conhecida a relação entre a profissão e o ideário católico, materializado, naquele período histórico, através da Doutrina Social da Igreja. A Igreja, que sempre dominou, até então, a organização das políticas sociais, é acionada pelo Estado para formar profissionais que pudessem se constituir como instrumento para o controle e adaptação da classe trabalhadora às novas configurações do mercado industrial. Esta relação Estado-IgrejaServiço Social imprime a profissão o caráter de apostolado.

A autora aponta que os fundamentos do Serviço Social se pautam, naquele período, na compreensão da questão social como problema moral e religioso e direciona a intervenção do profissional para conjunto de práticas que prioriza a formação da família e do indivíduo para o atendimento de suas necessidades materiais, morais e sociais. Ao Serviço Social passa ser atribuída a função de modelar comportamentos e valores para que os indivíduos pudessem se adaptar a ordem social. Tal significado da profissão é orientado por princípios humanistas conservadores.

$\mathrm{Na}$ década de 40, o Serviço Social passa a ser tecnificado ao receber influência do Serviço Social Norte-Americano. Suas propostas de trabalho começam a serem permeadas pelo caráter conservador da teoria social positivista. (YAZBEK, 2000)

Tal movimentação está relacionada à própria reconfiguração do Estado no tocante à organização das políticas sociais. Este, naquele momento, passa assumir, de forma direta, a execução dos programas sociais e exige a qualificação técnica do profissional. Há uma junção do discurso humanista cristão com o suporte técnico-científico de inspiração na teoria positivista. O Serviço Social passa a ser mediado não só pelo referencial doutrinário da Igreja Católica, mas também pelo legado conservador das Ciências Sociais.

Neste cenário, o horizonte analítico do Serviço Social aborda as relações sociais dos indivíduos no plano de suas vivências imediatas. Os fatos são fragmentados do conjunto das relações sociais. A prática deveria ser direcionada para ajustar e conservar o modo de organização das relações sociais, dado como algo natural entre os homens. Prioriza-se o aperfeiçoamento dos instrumentos e técnicas e ação profissional se molda a partir da burocratização das atividades institucionais.

Ainda segundo Yazbek, somente a partir da década de 60, inicia-se processo de questionamento do significado do Serviço Social no Brasil. A aproximação do Serviço Social com os movimentos sociais (que emergem no cenário político, produzindo resistências e combates à Ditadura Militar) e, conseqüentemente com a teoria marxista militante, desencadeia processo de questionamento (inicialmente do ponto de vista sócio-político e posteriormente do ponto de vista teórico) em relação ao atrelamento da profissão aos interesses da classe burguesa e de sua prática institucional que objetivava a adaptação social dos sujeitos.

No início dos anos 80, com a produção teórica de Marilda Iamamoto, são lançadas as bases para a reorientação teórico-metodológica, ético-política e técnico-operativa da profissão. Novos pressupostos de análises são construídos, a partir da fundamentação da teoria crítica de Marx, para compreensão do significado do 

projeto ético-político para a profissão (YAZBEK, 2000).

O projeto ético-político da categoria profissional, materializado no Código de Ética Profissional e na Lei de Regulamentação da Profissão, se consolida na década de 90 e redireciona o significado da profissão. A opção pelo atrelamento da profissão a projetos societários que postulam a emancipação humana como paradigma central, produziu novos princípios éticos para o exercício da profissão.

Os princípios da defesa da democracia, das políticas públicas, dos direitos sociais, civis e políticos, da eliminação de toda forma de preconceito e toda forma de exploração, impõem uma nova lógica para o trabalho do assistente social.

O assistente social que se situa neste debate contemporâneo sobre a profissão, percebe-se cercado por inúmeros desafios em seu cotidiano profissional. Como materializar os princípios éticos do Serviço Social? Como romper com a expectativa de que o assistente social vai reproduzir um trabalho conservador? Como não sucumbir aos interesses de quem detém o poder institucional?

As respostas a essas indagações podem estar relacionadas com a produção de competência teórica que habilite o profissional a decifrar a realidade social que o cerca. É preciso compreender que a instrumentalidade do trabalho do assistente social não se refere apenas ao conjunto de instrumentos e técnicas que dispõe para intervir na realidade social. É preciso estar atento à dimensão investigativa de seu trabalho, privilegiando a atividade da pesquisa como indispensável ao seu exercício profissional. Neste sentido, a fundamentação teórica deve ser reconhecida como componente fundamental desta instrumentalidade do seu trabalho.

3. Os Aspectos Teórico-metodológicos, Éticopolíticos e Técnico-operativos na Realização do Estudo e na Emissão do Parecer Social

\subsection{As dimensões interventiva e investigativa do trabalho do assistente social}

"Em Serviço Social, o saber crítico aponta para o saber fazer crítico" (BATISTA, 1992: 89) do trabalho do assistente social: a interventiva e a investigativa. Conforme já enunciado anteriormente, a profissão está inscrita na divisão social e técnica do trabalho, ou seja, no bojo das relações sociais são construídas necessidades e expectativas de que determinadas intervenções de sejam realizadas por este profissional.

Planejando, gerenciando e/ou executandopolíticassociais, públicasouprivadas, ou ainda assessorando outros profissionais através da elaboração de laudos e pareceres, o assistente social se aproxima do mundo real. É neste contexto que são apresentadas a demanda de trabalho para o assistente social.

Segundo Myrian Veras Batista (1992), esta aproximação com o mundo real é o "lado" mais aparente da ação do serviço social. "É aquele que se efetiva por aproximações - em resposta a questões imediatas, postas no cotidiano - que se fazem tendo como ponto de partida, muitas vezes, soluções provisórias e imediatistas”. (BATISTA, M.V.,1992: 90)

Entretanto, postula a autora, que toda prática se constitui a partir de uma referência inscrita no campo da consciência, mesmo que tal prática seja a mais utilitária e a mais rotineira. Tal referência à consciência ocorre, pois a intencionalidade da ação precede objetiva e cronologicamente a intervenção.

Esta intencionalidade tem sido construída historicamente pela profissão, no bojo de sua relação com as ciências sociais (que, por sua vez, se situa na relação Estado-Sociedade). É no processo histórico de produção das fundamentações teórico-metodológicas, éticopolíticas e técnico-operativas do serviço social que emerge a base para a construção destas intencionalidades do trabalho do assistente social.

A construção de uma intencionalidade está diretamente vinculada a um movimento da consciência que reconhece que não se pode atuar desconhecendo os objetos e processos sociais sobre os quais pretende intervir. Aqui se identifica a dimensão investigativa do trabalho do assistente social. Como será analisado teoricamente o objeto de intervenção que se apresenta como demanda de trabalho?

O referencial crítico de análise das relações sociais afirma que a essência de tais relações são ocultadas: não é percebida, à primeira vista, na imediaticidade dos fatos. Assim, é preciso desvelar o real: conhecer aquilo 
que o determina historicamente.

Este movimento de produção de conhecimento contribui para a superação do atendimento às demandas imediatas que emergem do cotidiano, que acabam fazendo do assistente social um mero tarefeiro.

O profissional impregnado da perspectiva investigativa é aquele que se mostra capaz de reconstruir seu objeto de intervenção. Tal reconstrução se faz essencial para romper com a prática do tarefeiro (atender às demandas imediatas do cotidiano) e trabalhar na perspectiva da emancipação humana, na defesa intransigente dos direitos, da democracia, da eliminação do preconceito etc. "Esta reconstrução do objeto significa o equacionamento das demandas que chegam ao assistente social, seja pela via da instituição, seja pela via dos usuários de seus serviços" (BATISTA, 1992).

Reconstruir o objeto significa, através da atividade da pesquisa, ser capaz de analisá-lo teoricamente.

\subsection{Os elementos constitutivos do parecer social}

O estudo social e o parecer técnico compõem, em uma primeira análise, a dimensão investigativa do exercício profissional, compreendida aqui como uma dimensão que aglutina a atividade de pesquisa situada no campo das ciências sociais.

SILVA (2000) pontua que, quando o assistente social é acionado para elaborar um parecer social, a demanda que lhe é apresentada se situa em torno da produção de conhecimentos acerca da vida de sujeitos sociais para subsidiar as decisões de outrem.

É considerado como processo através do qual o assistente social realizará estudo sobre uma dada realidade social e emitirá sua opinião técnica sobre a mesma.

Mioto (2001) pontua que os elementos constitutivos do parecer social estão relacionados com a finalidade direta e específica a qual se destinam. Por isso, é de fundamental importância identificar PARA QUÊ o parecer social está sendo produzido.

Frente ao exposto, a referida autora indica quais são os elementos que sustentam a emissão do parecer social:

- Competência Técnica: refere-se à habilidade do profissional no planejamento e execução do processo de realização do estudo social e elaboração do parecer;

- Competência teórico-metodológica: referese à fundamentação teórica que o profissional deve dispor para analisar os dados obtidos durante a realização do estudo social. O assistente social deve ter conhecimentos aprofundados sobre as temáticas que envolvem a matéria sobre a qual irá emitir seu parecer (conhecimentos acerca da produção existente no campo das ciências sociais e ainda no campo da legislação contemporânea sobre a matéria);

- Autonomia: refere-se á construção de sua liberdade para decidir acerca 1) dos instrumentos operativos que serão utilizados durante a realização do estudo social; 2) da indicação dos sujeitos que serão envolvidos no processo de feitura do estudo social; 3) da opção teórica que vai fundamentar a análise dos dados; 4) da escolha das informações que serão registradas no relatório, tendo em vista o sigilo profissional;

- Compromisso ético: refere-se à necessidade de incorporação dos princípios e das normas para o exercício profissional explicitadas no Código de Ética e na Lei de Regulamentação da Profissão. Neste sentido, se constitui como dever do assistente social: 1) informar aos sujeitos envolvidos na atividade as implicações em sua vida, decorrentes da realização do estudo social e a emissão do parecer; 2) resguardar o sigilo profissional; 3) não pretender aferir a verdade ou a mentira dos fatos; 4) não se basear em julgamentos de valores ou em atitudes moralistas ou preconceituosas; 5) compreender o parecer social como instrumento de viabilização dos direitos dos sujeitos envolvidos na atividade.

Mioto (2001) explicita ainda os princípios que devem nortear a ação do profissional que elabora o parecer social. A autora destaca que:

- "Toda situação é uma situação a ser desvelada”. Este princípio é importante para que o profissional mantenha postura de distanciamento, de "curiosidade" frente ao processo de desvelamento da realidade que será pesquisada. Não se pode antecipar uma análise sem que existam dados para fundamentá-la. É importante ainda que o assistente social não se guie apenas por fatos e datas para construir as histórias dos sujeitos. As "versões", os múltiplos "significados" atribuídos por cada 
um é material precioso para a compreensão da realidade. Outrossim, as predefinições ou as avaliações de outros profissionais não devem condicionar o resultado do parecer social. Em muitas situações, muitos outros profissionais de outras áreas já construíram suas análises (baseados em argumentos científicos ou no senso comum). $\mathrm{O}$ trabalho do assistente social tem uma especificidade e o profissional não pode se deixar guiar por referenciais de outras disciplinas;

- "Todo processo de realização do estudo social e elaboração do parecer é um processo de intervenção". Este princípio contribui para a desconstrução da idéia de neutralidade profissional. $\mathrm{O}$ trabalho de emissão do parecer provoca transformações na vida dos sujeitos envolvidos. Há que se perceber o aspecto paradoxal da realização deste trabalho: mesmo que expresse a dimensão investigativa da ação do assistente social, também se constitui como momento de intervenção;

- "A realização do estudo social e a elaboração do parecer implicam em transformações na vida dos sujeitos envolvidos na atividade". Em todos os momentos desse trabalho, é preciso que o assistente social esteja atento aos impactos que sua ação provoca na vida dos sujeitos. É preciso, então, ter um compromisso ético com cada sujeito que participa deste processo. $\mathrm{O}$ assistente social deve ainda ter habilidades para definir quais dados serão publicizados no relatório, tendo em vista as inúmeras pessoas e profissionais que terão acesso ao material;

- "O parecer deve situar-se no âmbito da competência do Serviço Social". Este princípio explicita a necessidade do profissional emitir, de forma clara e objetiva, sua análise, sem entrar no mérito da decisão que é de competência de outros profissionais. $\mathrm{O}$ assistente social deve ainda recortar como objeto de análise questões relacionadas à sua matéria.

\subsection{Realizando o estudo e elaborando o parecer social}

Conforme explicitado anteriormente, esse trabalho do assistente social expressa a dimensão investigativa da ação profissional; está associado ao campo da atividade da pesquisa social (conferir debate acerca da atividade de pesquisa no campo das ciências sociais em MINAYO, 1992).

O estudo social é o momento em que o assistente social vai construir o seu plano de trabalho e estabelecer o contato direto com a realidade que objetiva conhecer. $\mathrm{O}$ parecer social é o momento da análise, da emissão da avaliação do profissional acerca do objeto que foi delimitado no estudo social.

Assim, identifica-se a existência de duas fases no processo de realização do estudo social: a construção do plano de trabalho e a realização do trabalho de campo.

É de extrema importância que o profissional possa planejar suas ações. O plano de trabalho se apresenta como estratégia de planejamento para nortear o trabalho de campo. Nesta fase o assistente social vai identificar ou definir:

-Qual é o objeto de estudo?

A construção do objeto do estudo social está relacionada à análise das peculiaridades

sócio-institucionais. Deve ser identificado pelo assistente social e não por outros profissionais. Em linhas gerais, se constitui da singularidade da realidade das relações sociais nas quais os sujeitos sociais estão inseridos; das especificidades do processo de reprodução material e subjetiva da vida social dos sujeitos envolvidos.

- Quais são os objetivos do estudo social?

É o momento que o profissional define o quê pretende conhecer acerca da realidade de vida dos sujeitos envolvidos na atividade. A construção de tais objetivos também está associada ao reconhecimento das especificidades do estudo social demandado em cada tipo de ação judicial.

Identifica-se que, comumente, dentre outros, o profissional estabelece como objetivos: 1) conhecer as condições sócio-econômicas (inserção no mercado de trabalho, renda familiar, benefícios); 2)conhecer as condições sócio-habitacionais (infra-estrutura da moradia, de serviços de abastecimento de luz, água e recolhimento de esgotos, habitabilidade etc); 3)conhecer a composição e arranjo familiar; 4)conhecer a rede de (des) proteção social onde estão inseridos; 5)conhecer o modo de organização da família para atender as necessidades de seus membros; 6) conhecer as representações dos sujeitos sobre sua história de vida, sua realidade e a situação que se constitui como alvo de intervenção da instituição. 
Destaca-se que, privilegiar a fala dos sujeitos (que carrega significados sobre sua própria história, condições de vida, situação específica vivenciada junto a Justiça) é de extrema importância para a construção dos objetivos do estudo social. Em muitas ocasiões, os sujeitos terão apenas aquele espaço para se manifestarem diretamente. Privilegiar a análise dos fenômenos pela ótica de quem os vivencia deve ser um compromisso ético na realização do estudo social.

- Quais são as finalidades do estudo social?

È o momento em que o assistente social define o para quê e o porquê se deve realizar o estudo. Na construção das finalidades do estudo, deve-se estar atento para a necessidade de materialização dos princípios éticos do assistente social. O profissional não pode ceder às tendências conservadoras e burocratizantes das instituições. A finalidade última do estudo social deve estar relacionada com a garantia dos direitos sociais, políticos e civis dos sujeitos envolvidos.

- Quais os instrumentos que deverão ser utilizados para que o estudo social seja realizado?

É o momento em que o assistente social define quais são os instrumentos que irá utilizar para materializar os objetivos do estudo e ter acesso aos sujeitos que participarão da atividade. Vale lembrar da autonomia do profissional para a escolha de tais instrumentos. Dentre eles, pode-se destacar: entrevistas; visita domiciliar; visitas a instituições; observação participante; leitura de documentação etc.

- Quais são os sujeitos e/ou instituições que serão envolvidos no estudo social?

Este é o momento de se definir quem vai participar do estudo social. Esta escolha está atrelada aos objetivos do estudo e as especificidades do trabalho. É importante também que o assistente social defina como e quando tais sujeitos serão acionados, pois é justamente nesta ocasião que a interação com os sujeitos começa a acontecer.

Após a elaboração do plano de trabalho, o profissional vai iniciar a segunda fase da realização do estudo social, que se refere ao trabalho de campo propriamente dito. Nessa segunda fase, efetivamente, o assistente social estabelece a relação com os sujeitos e aplica os instrumentos para a coleta dos dados empíricos, segundo seus objetivos. O ideal é que o processo de abordagem seja documentado, preferencialmente, através de relatórios parciais descritivos. Vale ressaltar que essa documentação não deve ser encaminhada no relatório final. Ela pode ser arquivada em locais que somente o Serviço Social tenha acesso.

Esses relatórios parciais servirão de base para análise dos dados e elaboração do relatório final, em que será explicitado o parecer social.

Vale destacar ainda que, frente à dinamicidade da realidade, o assistente social necessita rever seu planejamento em função das informações que obtém durante o seu trabalho de campo.

Após a feitura do estudo social, o profissional vai se debruçar na análise dos dados obtidos. Assim, de posse dos dados empíricos, o assistente social vai estabelecer conexões com o referencial teórico que o embasa; vai estabelecer a relação entre o singular e o universal das relações sociais. É sabido que realidade não pode ser apreendida em sua totalidade pelo movimento da razão. Então, o movimento para compreendê-la apenas se aproxima do real (PONTES, 1997).

Frente ao exposto, é preciso ter fundamentação para estabelecer articulações entre as situações singulares vivenciadas pelos sujeitos e os processos de organização da cultura, da política, da economia, por fim, da reprodução material e subjetiva dos homens.

É preciso ainda ter conhecimento sobre a relação Estado/Sociedade, principalmente ao que se refere à organização das políticas sociais. É preciso também conhecer a legislação social vigente, na perspectiva de fundamentar as análises propostas.

O parecer social será emitido através de relatório (ou laudo social). Esse documento deve conter, fundamentalmente, a análise que o assistente social realizou sobre a situação que lhe foi apresentada. É importante que o profissional contextualize para o leitor o processo de realização do estudo social (instrumentos utilizados, sujeitos que foram envolvidos). $\mathrm{O}$ assistente social pode ainda explicitar um resumo dos dados obtidos através da realização do estudo social, observando o sigilo profissional.

O profissional pode também propor alternativas, apontar as necessidades dos sujeitos, sugerindo encaminhamentos. Entretanto, é importante relembrar que não deve entrar no mérito da decisão que não é de sua competência. 
É preciso que cada alternativa ou sugestão esteja fundamentada.

É importante estar atento para o uso da linguagem, obedecendo às regras da língua portuguesa (destacando o tratamento que deve ser dado as autoridades envolvidas). Em relação à formatação do relatório, cada profissional deve criar seu estilo.

Deleuze:

E para concluir, parafraseando

"É preciso falar da criação como traçando seu caminho entre impossibilidades... a criação se faz em gargalos de estrangulamento...se um criador não é agarrado pelo pescoço por um conjunto de impossibilidades, não é um criador. Um criador é alguém que cria suas próprias impossibilidades, e ao mesmo tempo cria um possível...pois sem um conjunto de impossibilidades não se terá essa linha de fuga, essa saída que constitui a criação.” (DELEUZE: 1992, 166)

\section{Referências}

- ANTUNES, R. Adeus ao Trabalho? Ensaio sobre as Metamorfoses e a Centralidade do Mundo do Trabalho. São Paulo, Cortez: 2002.

- BATISTA, M. V. A produção do conhecimento social contemporâneo e sua ênfase no Serviço Social. Cadernos ABESS, no 05, São Paulo: Cortez, 1992.

- DELEUZE, G. Conversações. São Paulo: Editora 34, 1992.

- FARIA, J. O poder judiciário nos universos jurídicos e sociais: esboço para uma discussão de política judicial comparada. Serviço Social e Sociedade, $n^{\circ}$ 67, ano XXII, São Paulo: Cortez, 2001.

- FÁVERO, E. O estudo social; fundamentos e particularidades de sua construção na área judiciária. CFESS (org). O Estudo Social em Perícias, Laudos e Pareceres Técnicos. São Paulo: Cortez, 2003.
- GUERRA, I. Instrumentalidade do Processo de Trabalho e Serviço Social .Serviço Social e Sociedade, $n^{\circ}$ 62, ano XXI, São Paulo: Cortez, 2000.

- IAMAMOTO, M. Projeto profissional e trabalho do assistente social: o Serviço Social no Tribunal de Justiça do Estado de São Paulo. FÁVERO, E et ali (org). O Serviço Social e a psicologia no Judiciário. São Paulo: Cortez, 2005.

\section{Serviço Social na}

Contemporaneidade: trabalho e formação profissional. São Paulo: Cortez, 2000.

$-$ Questão social, família e juventude: desafios do trabalho do assistente social na área sócio-jurídica. SALES, M. et ali (org). Política Social, Família e Juventude: Uma Questão de Direitos. São Paulo: Cortez, 2004.

- MINAYO, M. O desafio do conhecimento. São Paulo-Rio de Janeiro: Hucitec- Abrasco, 1992.

- MIOTO, R. Perícia Social: proposta de um percurso operativo. Serviço Social e Sociedade, nº 67, ano XXII, São Paulo: Cortez, 2001.

- PONTES, R. Mediação e Serviço Social. São Paulo: Cortez, 1997.

- SILVA, M. Um novo fazer profissional.CFESSABEPSS- CEAD/NED -UnB. O trabalho do assistente social e as políticas sociais. Brasília: UnB, 2000.

- YASBEK, M. Os fundamentos do Serviço Social na contemporaneidade.CFESSABEPSS- CEAD/NED -UnB. $O$ trabalho do assistente social e as políticas sociais. Brasília: UnB, 2000.

\section{Informação bibliográficas:}

Conforme a NBR 6023:2002 da Associação Brasileira de Normas Técnicas (ABNT), este texto científico publicado em periódico eletrônico deve ser citado da seguinte forma:

BARISON, Mônica Santos. O Trabalho do Assistente Social no Poder Judiciário: a realização do estudo social e a elaboração do parecer técnico. Cadernos UniFOA, Volta Redonda, ano III, n. 6, abril. 2008. Disponível em: <http:/www.unifoa.edu.br/pesquisa/caderno/edicao/06/49.pdf> 